\title{
O distrito e a rede urbana: percepções a partir do distrito de Cipolândia, Aquidauana (MS), Brasil
}

\author{
The district and the urban network: perceptions from \\ Cipolândia district, Aquidauana (MS), Brazil
}

\section{El distrito y la red urbana: percepciones del distrito de Cipolândia, Aquidauana (MS), Brazil}

\author{
Geovandir André Lordano \\ https:/ / orcid.org/0000-0001-8372-5354 \\ geovandirlordano@gmail.com \\ Universidade Federal de Mato Grosso do Sul, UFMS, Aquidauana, MS \\ Paulo Roberto Joia \\ https:/ / orcid.org/0000-0001-6198-6713 \\ paulo.joia@ufms.br \\ Universidade Federal de Mato Grosso do Sul, UFMS, Aquidauana, MS
}

Resumo: É de consenso geral reconhecer as dificuldades de acessibilidade da população aos serviços urbanos disponíveis. Ao se reportar às áreas rurais, a acessibilidade torna-se mais dificultosa. Este artigo tem como objetivo analisar a acessibilidade dos moradores do distrito rural de Cipolândia, localizado no município de Aquidauana/ MS, aos serviços urbanos disponíveis na rede urbana regional. Trata-se de uma pesquisa descritiva, quali-quantitativa, que se apoia inicialmente em referências bibliográficas e documentais, e em pesquisa de campo por meio da observação direta e da aplicação de formulários. Como resultados, destacam-se que a sede do distrito, ainda que no desempenho das funções urbanas mais básicas, possui equipamentos e serviços que proporcionam um primeiro contato de seus moradores com a rede urbana regional, embora com flagrantes limitações. A cidade de Aquidauana é o principal centro urbano para o acesso à rede urbana, tendo, assim, maior influência sobre os moradores do distrito de Cipolândia, sobretudo para a satisfação dos bens e serviços mais elementares como a realização de compras e serviços bancários. Contudo, quando a busca está relacionada a serviços que requerem maior especialização, a Capital Regional, Campo Grande, é a que exerce maior influência, atraindo maior parte dos deslocamentos. No geral, o acesso à rede urbana é facilitado no sentido à cidade de Aquidauana, pelas boas condições da rodovia MS-345, enquanto para o acesso à Campo Grande, o sistema viário apresenta piores condições de trafegabilidade.

Palavras-chave: Acessibilidade, Sistema viário, Funções urbanas.

Abstract: It is a consensus to recognize the population's accessibility difficulties to the available urban services. When referring to rural areas, accessibility becomes even more difficult. This article aims to analyze the accessibility of the residents of the 
rural district of Cipolândia, located in the municipality of Aquidauana/Mato Grosso do Sul State, to urban services available in the regional urban network. Performing a descriptive, qualitative, and quantitative research, supported by bibliographic and documentary research in addition to field research through direct observation and forms application. As a result, it is noteworthy that the district headquarters, although in the performance of the most basic urban functions, has equipment and services that provide the first contact of its residents with the regional urban network, yet with striking limitations. The city of Aquidauana is the main urban center for access to the urban network, thus having a greater influence on the residents of the Cipolândia district, especially for the satisfaction of more basic goods and services such as shopping and banking services. However, when the search is related to services that require greater specialization, the Regional Capital, Campo Grande, is the one that exerts the greatest influence, attracting most of the displacements. In general, access to the urban network is facilitated towards the city of Aquidauana, due to the good conditions of the MS-345 highway, whereas to access Campo Grande, the road system presents worse traffic conditions.

Keywords: Accessibility, Road System, Urban functions.

Resumen: Es un consenso general reconocer las dificultades de accesibilidad de la población a los servicios urbanos disponibles. Al referirse a las zonas rurales, la accesibilidad se vuelve más difícil. Este artículo tiene como objetivo analizar la accesibilidad de los residentes del distrito rural de Cipolândia, ubicado en el municipio de Aquidauana / MS, a los servicios urbanos disponibles en la red urbana regional. Es una investigación descriptiva, cualitativa y cuantitativa, que inicialmente se basa en referencias bibliográficas y documentales, y en la investigación de campo a través de la observación directa y la aplicación de formularios. Como resultado, es digno de mención que la sede del distrito, incluso en el desempeño de las funciones urbanas más básicas, cuenta con equipos y servicios que proporcionan un primer contacto de sus residentes con la red urbana regional, aunque con limitaciones notables. La ciudad de Aquidauana es el principal centro urbano para el acceso a la red urbana, por lo que tiene una mayor influencia en los residentes del distrito de Cipolândia, especialmente para el acceso a bienes y servicios más básicos como compras y servicios bancarios. Sin embargo, cuando la búsqueda se relaciona con servicios que requieren una mayor especialización, la Capital Regional, Campo Grande, es la que ejerce la mayor influencia, atrayendo la mayoría de los desplazamientos. Por lo general, el acceso a la red urbana se encauza hacia la ciudad de Aquidauana, debido a las buenas condiciones de la carretera MS-345, mientras que, para el acceso a Campo Grande, el sistema de carreteras presenta peores condiciones de tráfico.

Palabras clave: Accesibilidad, Sistema de caminos, Funciones urbanas.

\section{INTRODUÇÃO}

O distrito municipal é uma subdivisão administrativa dos municípios, a menor no âmbito nacional. Com objetivo de melhorar o processo de planejamento e da implantação e desenvolvimento das ações e políticas públicas, uma atenção dada aos distritos possibilita que os municípios sejam mais bem administrados (Abramovay, 2000; Silva, 2014). Em linhas gerais, os distritos municipais rurais caracterizam-se por serem territórios compostos de uma sede distrital e de um excedente territorial rural. Legalmente, a sede distrital é considerada, para fins de recenseamento populacional, pelo critério de divisão administrativa, como uma área urbana (Instituto Brasileiro de Geografia e Estatística [IBGE], 2013b). 
No século XXI, parece não haver contestações de que a maior parte da população brasileira está inserida em uma rede urbana, seja diretamente no caso dos que residem nas cidades e nos núcleos urbanos, seja indiretamente no caso dos que residem no campo, os quais também estão sob uma área de influência de uma rede urbana. Neste sentido, a sede do distrito, considerando as particularidades do território distrital em análise, pode assumir um papel de ponto de interseção entre os moradores do campo e a rede urbana, ainda que pelo desempenho das funções mais elementares à vida cotidiana, como as atividades comerciais, os serviços bancários e os serviços estatais de educação e de saúde, entre outros. Por outro lado, a sede do distrito pode possuir pouca ou nenhuma influência na satisfação das demandas dos moradores, os quais teriam, nas cidades que a circundam, o desempenho não apenas das funções mais especializadas, mas também das mais elementares.

Este artigo parte do questionamento de como o distrito de Cipolândia, localizado no município de Aquidauana, no estado de Mato Grosso do Sul, insere-se na rede urbana e qual a configuração de sua sede face ao desempenho de funções urbanas essenciais a seus moradores e o acesso dos moradores do distrito à rede urbana. De forma mais específica, busca caracterizar a sede do distrito de Cipolândia quanto aos seus equipamentos urbanos, identificar quais as cidades são acessadas pelos moradores para a realização de suas atividades cotidianas e analisar as condições de acessibilidade à rede urbana.

Ademais, este artigo tem a pretensão de incluir o distrito rural no debate da rede urbana em escala nacional e regional, enquanto unidade administrativa que, academicamente e administrativamente, é uma das mais negligenciadas nesse tipo de estudo.

\section{PROCEDIMENTOS METODOLÓGICOS}

A moldura da amostragem para o levantamento em campo foi a população do distrito com 15 anos de idade ou mais. A amostra estratificada (Tab. 1) foi composta de 86 indivíduos residentes no distrito de Cipolândia, distribuída em uma proporcionalidade aceitável como estrutura da população total considerando sexo, faixa etária e situação de moradia (urbana ou rural) com base no Censo Demográfico de 2010. Para Babbie (1999), a amostra estratificada é um método que possibilita um maior grau de representatividade, reduzindo um possível erro amostral. Nesta pesquisa, o erro amostral máximo desejado foi de $10 \%$.

Os formulários foram aplicados nos meses janeiro, fevereiro e março de 2019, oportunidades nas quais também se desenvolveu a observação direta, a qual teve seus dados coletados por meio de registro fotográfico e anotações em caderneta de campo. 
Tabela 1: Amostra estratificada da população do distrito de Cipolândia, conforme gênero, faixa etária e situação de moradia.

\begin{tabular}{|c|c|c|c|c|c|}
\hline \multirow{3}{*}{ Faixa etária } & \multicolumn{4}{|c|}{ Situação de Moradia x Gênero } & \multirow{3}{*}{ Total } \\
\hline & \multicolumn{2}{|l|}{ Urbana } & \multicolumn{2}{|l|}{ Rural } & \\
\hline & Masculino & Feminino & Masculino & Feminino & \\
\hline População residente de15 a 24 anos & $29(4,90 \%)$ & $25(4,23 \%)$ & $25(4,23 \%)$ & $22(3,72 \%)$ & $101(17,08 \%)$ \\
\hline $\mathrm{N}^{\circ}$ de formulários aplicados & 4 & 4 & 4 & 3 & 15 \\
\hline População residente de 25 a 44 anos & $52(8,78 \%)$ & $66(11,16 \%)$ & $53(8,96 \%)$ & $47(7,94 \%)$ & $218(36,88 \%)$ \\
\hline $\mathrm{N}^{\circ}$ de formulários aplicados & 8 & 9 & 8 & 7 & 32 \\
\hline População residentes de 45 a 59 anos & $42(7,10 \%)$ & $35(5,92 \%)$ & $42(7,10 \%)$ & $33(5,58 \%)$ & $152(25,71 \%)$ \\
\hline $\mathrm{N}^{\circ}$ de formulários aplicados & 6 & 5 & 6 & 5 & 22 \\
\hline População residente com mais de 60 anos & $35(5,92 \%)$ & $38(6,42 \%)$ & $32(5,41 \%)$ & $15(2,53 \%)$ & $120(20,30 \%)$ \\
\hline $\mathrm{N}^{\circ}$ de formulários aplicados & 5 & 5 & 5 & 2 & 17 \\
\hline Total população residente com 15 anos ou mais & $158(26,75 \%)$ & $164(27,75 \%)$ & $152(25,70 \%)$ & $117(19,80 \%)$ & $591(100 \%)$ \\
\hline Total de formulários aplicados & 23 & 23 & 23 & 17 & 86 \\
\hline
\end{tabular}

Fonte: Sistema IBGE de Recuperação Automática (SIDRA, 2018)1.

A relação do distrito de Cipolândia com a rede urbana é abordada à luz dos deslocamentos cotidianos de seus moradores à cidade. A caracterização da sede distrital é realizada sob o prisma do desempenho das funções urbanas de distribuição de bens e serviços, as quais, para Corrêa (2018), são as funções mais características que um núcleo urbano desempenha na rede urbana. Por fim, a análise das condições de acessibilidade à rede focaliza as estradas e rodovias que possibilitam a interação entre o distrito de Cipolândia e as cidades acessadas pelos moradores.

Para a elaboração dos materiais cartográficos foi utilizado o software ArcGIS 10. Além da utilização dos dados primários colhidos a campo, também foram pesquisadas as bases do Instituto Brasileiro de Geografia e Estatística (IBGE, 2019), sobretudo os referentes à divisão político-administrativa e às rodovias.

\section{Localização e caracterização do distrito de Cipolândia}

O distrito de Cipolândia é parte do município de Aquidauana, o qual, além do distrito sede de Aquidauana, é constituído por mais outros três distritos: Camisão, Piraputanga e Taunay (IBGE, 2018). Cipolândia está localizada no planalto Aquidauana/Campo Grande, entre as coordenadas: $55^{\circ} 03^{\prime} 53^{\prime \prime}$ e $55^{\circ} 25^{\prime} 29^{\prime \prime}$ W e $19^{\circ} 57^{\prime} 06$ e $20^{\circ} 20^{\prime} 28^{\prime \prime} \mathrm{S}$ (Fig. 1 ).

Com área total de $767,817 \mathrm{~km}^{2}$, o distrito de Cipolândia faz divisa ao norte com o município de Corguinho; ao leste com os municípios de Corguinho e Terenos; ao sul com os municípios de Terenos e Dois Irmãos do Buriti; e ao oeste, limitado pelo rio Taboco, com o restante do território do município de Aquidauana. A sede do distrito de Cipolândia é composta por aproximadamente 43 quadras de loteamento residencial. No ano de 2010, o distrito de Cipolândia possuía uma população de 814 habitantes dos quais 437 moradores $(53,70 \%)$ residiam na sede do distrito e 377 moradores $(46,30 \%)$ residiam na área rural do distrito (IBGE, 2010).

1 Disponível em https://sidra.ibge.gov.br/tabela/1378. 
Figura 1: Localização do distrito de Cipolândia, Aquidauana, MS.

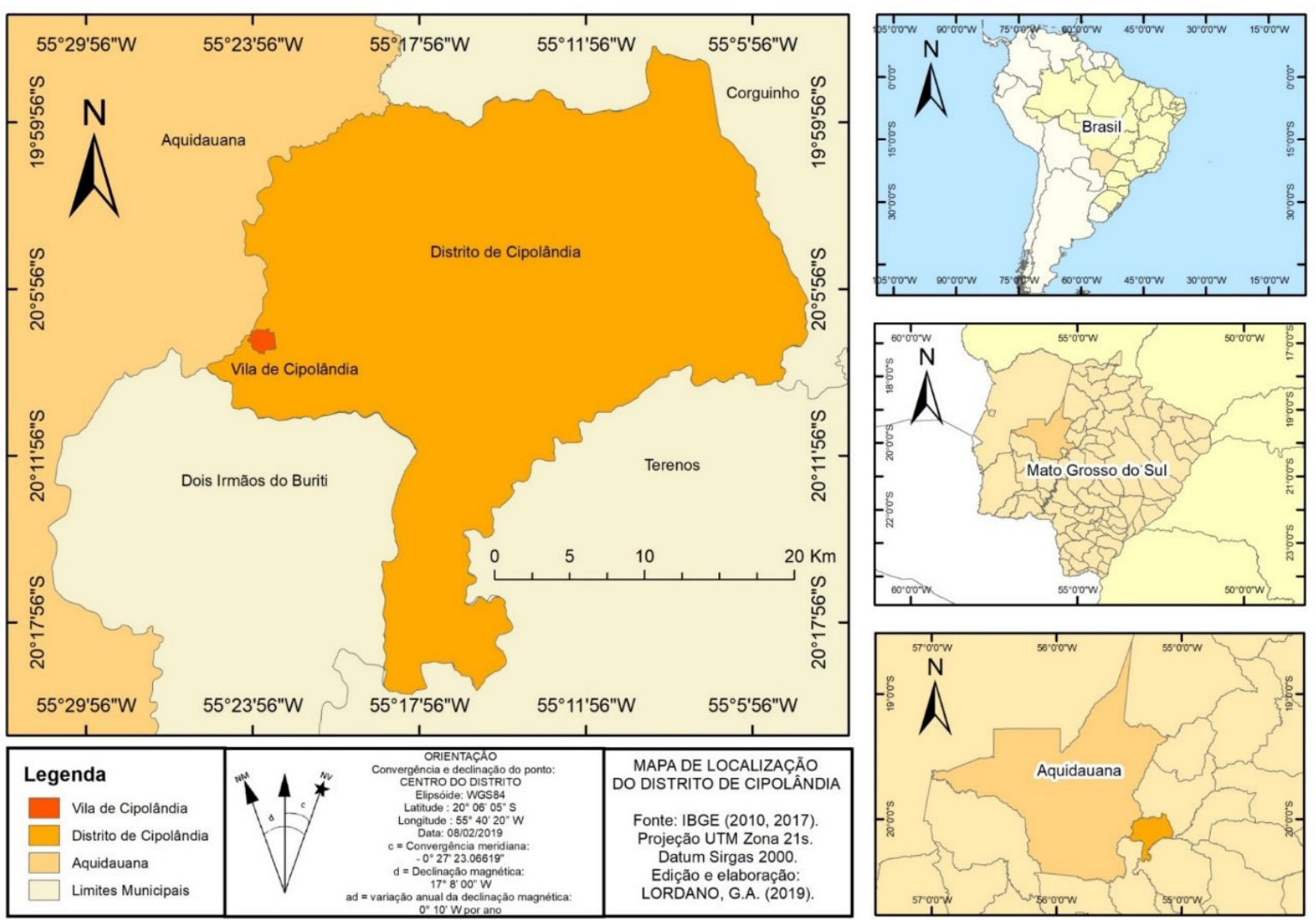

Economicamente, o distrito de Cipolândia caracteriza-se pela baixa dinamicidade de suas atividades. $\mathrm{O}$ predomínio do modelo produtivo que privilegia a grande propriedade rural é marcado pela dispersão populacional, a qual, segundo Keller (1970), é uma característica latente na paisagem rural brasileira oriunda do processo da colonização. As atividades agrícolas predominantes são a bovinocultura de leite e de corte (Silva, Cunha \& Bacani, 2018), com raras áreas de manejo de florestas plantadas de eucalipto, e ausência de agroindústrias.

Nesse sentido, o perfil socioeconômico dos moradores está muito ligado às atividades de prestação de serviços nas fazendas da região e, em alguns casos, à ocupação nos estabelecimentos comerciais na sede do distrito. Os núcleos familiares, em média, são compostos por 2,77 indivíduos. Quanto à ocupação, destaca-se que a maioria se declarou como "empregados" (25,58\%), "do lar" (25,58\%) e aposentados (19,77\%), sendo ainda 8,14\% prestadores de serviço sazonal/bico e 4,65\% funcionários públicos e militar (1,16\%). Dos demais, há estudantes (4,65\%), autônomos (3,49\%), empresários (3,49\%), pecuaristas $(2,33 \%)$ ou agricultor $(1,16 \%)$.

No que se refere à escolaridade, a metade dos moradores do distrito possui apenas o ensino fundamental incompleto (54,65\%). Dos demais, 10,47\% finalizaram o ensino fundamental, 10,47\% possuem o ensino médio incompleto e 13,95\% concluíram o ensino médio. Finamente, uma minoria cursou o ensino superior incompleto $(2,33 \%)$ ou finalizou o estudo superior (3,49\%). A renda familiar no distrito era de até $\mathrm{R} \$ 1$ mil mensais em 43,02\% dos casos; entre R\$ 1-2 mil mensais para 31,40\%; e de $\mathrm{R} \$ 2-5$ mil mensais para $25,58 \%$. 
Assim, no que se refere ao perfil socioeconômico, observou-se o baixo índice de escolaridade e a baixa renda familiar da população, em função das atividades econômicas predominantes e da oferta de trabalho, com predomínio da ocupação masculina nos trabalhos rurais e ocupação feminina restrita às lides do lar, repercutindo na baixa dinamicidade do desenvolvimento da comunidade local. Fatores que, entre outros, indicam um processo de urbanização do distrito com fortes influências das atividades rurais e, ao mesmo tempo, com exigência de investimentos em equipamentos e serviços urbanos necessários ao atendimento à população.

\section{DISTRITO MUNICIPAL E REDE URBANA: ALGUMAS QUESTÕES}

A subdivisão municipal no Brasil para fins administrativos e estatísticos é fortemente baseada no implemento, além do distrito sede (a cidade), dos distritos municipais - os quais, geralmente, são caracterizados por constituírem um pequeno centro de dimensões demográficas e sociais variadas - e de uma hinterlândia de proporções igualmente diversas.

Segundo o Instituto Brasileiro de Geografia e Estatística (IBGE, 2013a, 2013b), a sede do distrito é considerada urbana pelo simples fato de ser sede de uma divisão político administrativa. As sedes distritais (que recebem do IBGE a categoria de Vila) são consideradas urbanas, assim como quaisquer outras áreas urbanas isoladas, apesar de o Instituto admitir que nem todas as vilas criadas pelas legislações municipais possuem ocupação urbana. Em suma, o distrito é uma divisão territorial no interior do município e a ele subordinado administrativamente, que possui, para fins administrativos e estatísticos, uma sede considerada urbana e, em muitos casos, uma área excedente considerada rural.

Para Silva (2014), embora situado na zona rural do município, o fato de ser considerado urbano suscita que o distrito seja provido do aparato de políticas públicas e de equipamentos como as demais áreas urbanas do município. Esse fato, conforme Pina, Lima e Silva (2008), não se concretiza, pois apesar de alcançarem a categoria de distrito, continuam ainda dependentes dos serviços básicos situados no distrito sede do município - a cidade. Conforme Antunes e Hespanhol (2018), os distritos que não atingem status urbano suficientemente ao ponto de emancipar-se, mas que também não terminam desaparecendo diante da perda populacional, preservam, de um lado, laços intensos com o espaço rural e, de outro, uma grande dependência da sede do município.

Isso posto, a dependência do distrito e, consequentemente, de seus moradores à cidade, pode ver vista em duas perspectivas distintas, porém complementares, basilares para a análise deste artigo. A primeira é a ausência de estrutura interna do próprio distrito, sobretudo em sua sede. A segunda é o fato de o distrito encontrar-se inserido e/ ou submetido à rede urbana e, consequentemente, à área de influência e de atração das cidades que a compõe.

Sendo uma rede geográfica por excelência, para Corrêa (2018), a rede urbana tem despertado a atenção de geógrafos e não geógrafos há muito tempo, tendo, na proposição de Walter Christaller, na década de 1930, uma bem consolidada teoria sobre a rede 
urbana, a qual focaliza os centros urbanos enquanto lugares centrais para a distribuição de produtos industrializados e de prestação de serviços, tanto para a população residente quanto para a população de sua hinterlândia.

Apesar de Corrêa (2018) considerar a teoria dos lugares centrais como parcial, por não considerar as especificações produtivas dos centros urbanos, reconhece que a teoria chistalleriana é útil para a implantação de serviços públicos de demandas variadas espacialmente, assim como a distribuição de filiais de uma empresa, por exemplo. A teoria dos lugares centrais tornou-se objeto de interesse por parte do IBGE, desde a década de 1960, para a produção de trabalhos voltados à definição das regiões de influência das cidades e útil para o planejamento urbano e regional.

Nesse sentido, conforme a obra Regiões de influência das cidades - 2007, IBGE (2008), as cidades brasileiras podem ser hierarquizadas e classificadas em cinco grandes níveis, por sua vez subdivididos em dois ou três subníveis: Metrópoles (Grande Metrópole Nacional, Metrópole Nacional e Metrópole); Capital Regional (Capital Regional A, Capital Regional B e Capital Regional C); Centro Sub-Regional (Centro Sub-Regional A e Centro Sub-Regional B), Centro de Zona (Centro de Zona A e Centro de Zona B) e Centro Local.

Para Conte (2014), as funções centrais de um núcleo determinam seu grau de importância e, consequentemente, sua centralidade. Quanto maior o número de funções, maior a sua região de influência; quanto maior a população externa atendida pela localidade central, maior a sua centralidade. Logo,

... a oferta de bens e serviços está relacionada ao tamanho do núcleo e de sua área de influência. Nesta dinâmica ocorre a hierarquização entre os centros; uma das formas utilizadas é: metrópole regional, capital regional, centro sub-regional, centro de zona e centro local. (Conte, 2014, p. 77).

A rede urbana é o conjunto de centros urbanos e de suas hinterlândias, que se articulam funcionalmente, envolvendo uma complexa diferenciação entre as cidades. Reflexo e ao mesmo tempo condição social, a rede urbana constitui-se poderoso meio para a realização do consumo, da distribuição e da produção capitalista, a qual, amplamente especializada, pressupõe a existência da própria rede urbana (Corrêa, 2018).

Em uma visão citadina da questão, Corrêa (2018) salienta que a cidade, enquanto organismo funcional, mantém relações com o espaço exterior a ela, ou seja, com uma região na qual se constituem não apenas sua área rural, mas também outras cidades menores. Entre essas relações pode-se destacar, além da drenagem da renda fundiária, da comercialização dos produtos da economia rural e da distribuição de investimento e trabalho, seu poder de atração sobre a população regional e o fornecimento de bens e de serviços. Esse fornecimento é uma função comum aos centros urbanos que, inclusive, podem justificar sua existência, assim como os serviços administrativos e sociais, os serviços ligados ao lazer e ao turismo e os serviços ligados aos capitais.

Diante do exposto, a análise apresentada adiante focaliza a relação de influência da rede urbana sobre os moradores do distrito rural e, ainda, como o distrito também se 
insere na rede urbana regional como provedor das funções básicas inerentes aos centros urbanos, mesmo que nas funções mais elementares.

\section{RESULTADOS E DISCUSSÃO}

\section{A sede do distrito de Cipolândia, um ponto inicial à rede urbana}

Para a análise que se propõe, em um primeiro momento, faz-se necessário considerar o distrito rural em sua organização espacial presente, ainda que, para tal, seja imperativo que se conheçam e se considerem, ainda que em parte, os elementos de sua formação espacial.

Conforme Corrêa (2000), a formação espacial brasileira é muito heterogênea, a depender da escala de análise, e resulta de uma combinação desigual, tanto no espaço como no tempo, de processos naturais e sociais. No caso do distrito de Cipolândia, a organização espacial presente reflete os diferentes períodos históricos a que esteve submetido. Seu surgimento como povoado advém, inicialmente, da migração para a região de grande contingente de garimpeiros em busca de diamantes, na década de 1930. Após, com o declínio da mineração, a partir da década de 1950, foi importante colônia agrícola para o município de Aquidauana, com destaque ao cultivo do café, período em que teve seus primeiros equipamentos urbanos instalados em sua sede. Contudo, com o decorrer do tempo, passou a ser um distrito pouco atrativo economicamente, não alcançando maior desenvolvimento (Joia, 2005; Robba, 1992). Atualmente, na sede do distrito a única atividade industrial é a presença de uma indústria da cerâmica (Fig. 2).

Figura 2: Indústria de cerâmica na sede do distrito de Cipolândia.
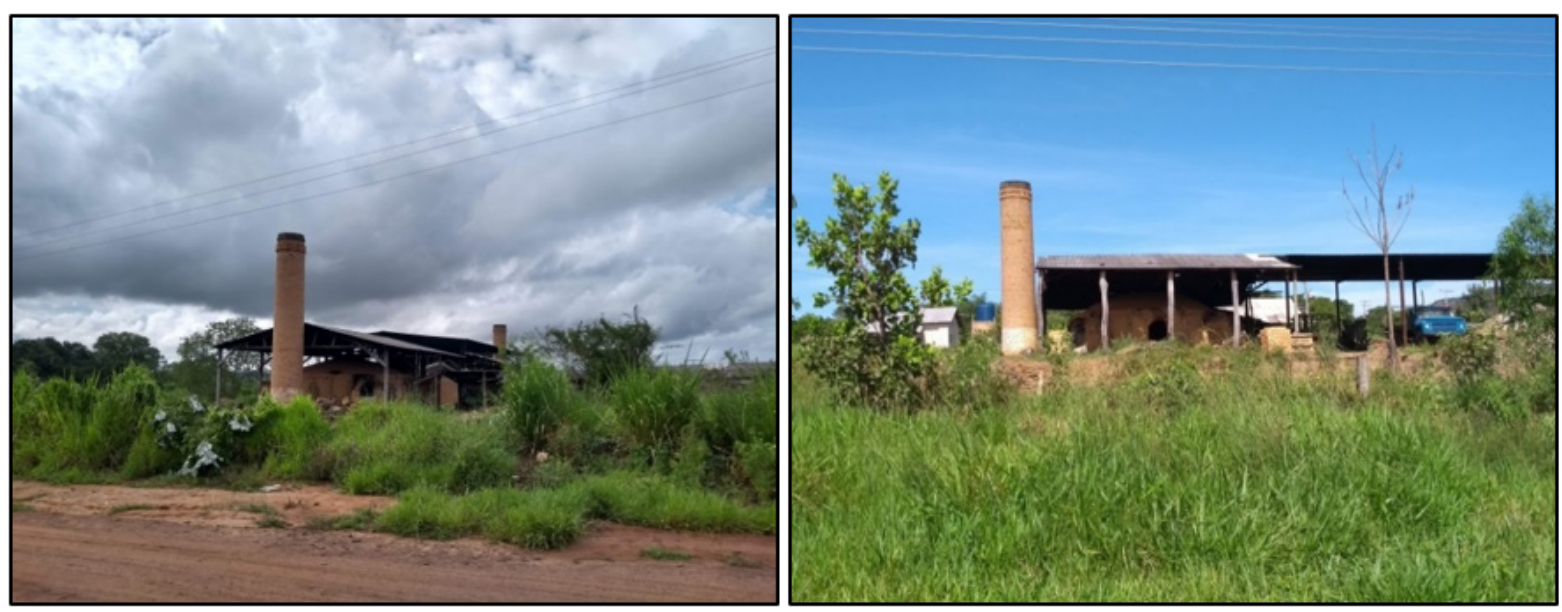

Outro pilar importante na economia do distrito é seu comércio varejista, ainda que pouco diversificado. Na sede distrital, observa-se a existência de apenas um mercado de secos e molhados (Fig. 3 A) de uma pequena loja de materiais de construção (Fig. 3 B) e de dois açougues. Porém, são as graves ausências estruturais que chamam mais atenção, como a falta de um posto de combustíveis operante, já que o posto local se encontra fechado há algum tempo (sendo o combustível no distrito comercializado em garrafas PET). Falta farmácia e serviços bancários, nem mesmo um caixa eletrônico. 
A sede do distrito conta com equipamentos de educação (Fig. 3 C) e de saúde (Fig. $3 \mathrm{D})$, sendo esses os principais no que se refere à presença estatal no distrito, tanto à luz dos serviços prestados quanto de seu impacto na economia de Cipolândia, sobretudo por meio da alocação de parte da mão de obra dos moradores do distrito.

Figura 3: Equipamentos de comércio (A e B), educação (C) e saúde (D) no distrito de Cipolândia.

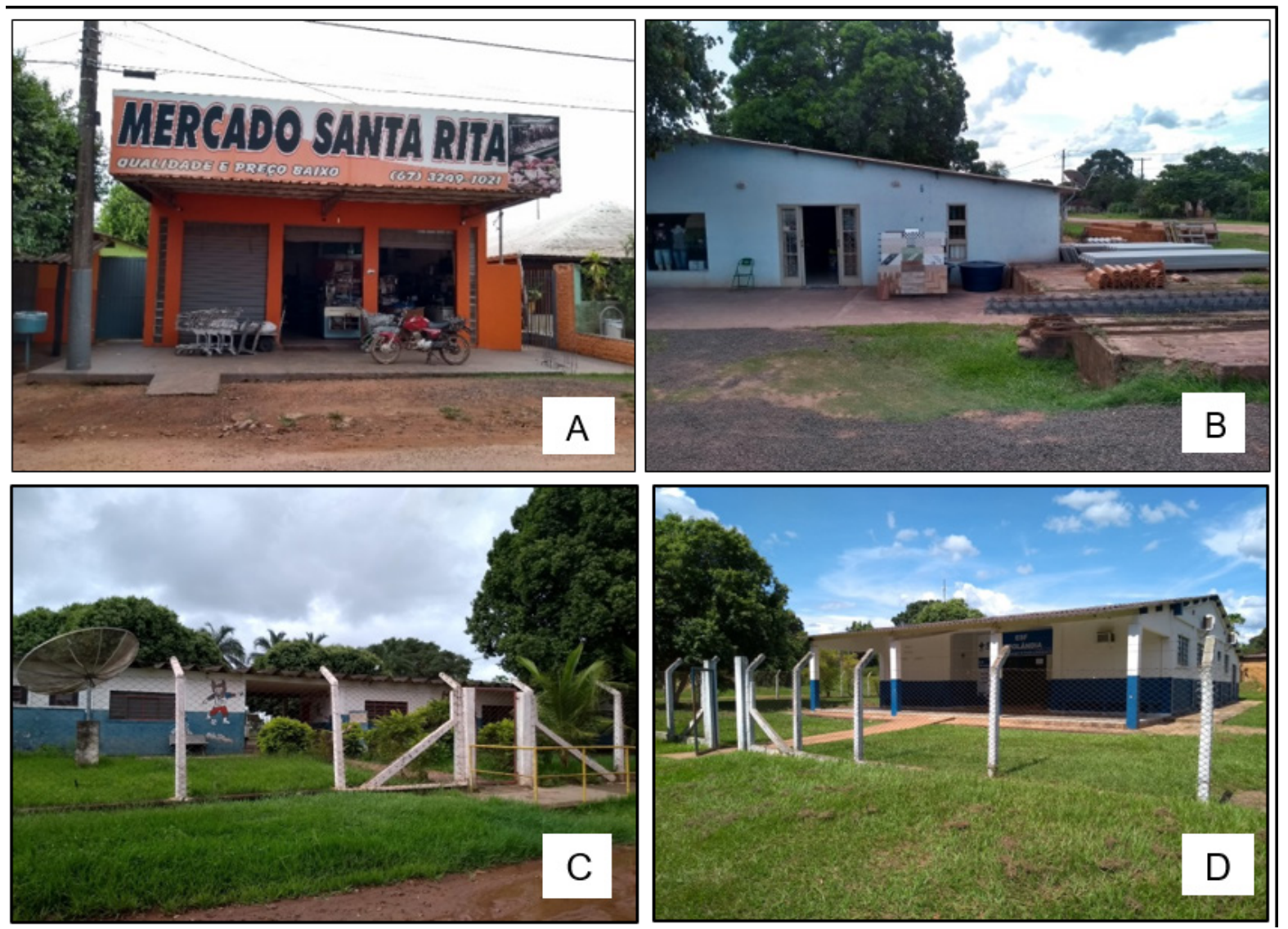

Essa conjuntura de presenças e de ausências, no que tange à distribuição de bens e serviços básicos, encontra amparo nas palavras de Corrêa (2000), que afirma que a rede urbana, mais que o mundo agrário, tende a ter os padrões de formas que contém os elementos gerados nas diversas formações espaciais a que esteve associada e, ainda, a exibir as características dos diversos momentos de sua formação histórica. De modo mais específico, percebe-se que os equipamentos urbanos presentes atualmente na sede do distrito de Cipolândia ainda são reflexos do momento histórico em que o distrito atingia seu apogeu, nos campos econômico, social ou político, e consequentemente suas ausências estão relacionadas a um período de estagnação.

O nível de satisfação dos moradores do distrito com os equipamentos para o desempenho das funções urbanas essenciais, como a distribuição de bens e serviços, pode ser verificado pela avaliação obtida na pesquisa de campo. $\mathrm{O}$ comércio ${ }^{2}$ no distrito foi

2 A avaliação do Comércio na sede do distrito de Cipolândia tomou como base exclusivamente os equipamentos destinados às compras pessoais e para a casa. 
avaliado como regular por 34,88\% dos entrevistados, havendo igualdade do índice dos que avaliaram como bom, ruim ou péssimo (17,44\% cada), além de 11,63\% que afirmaram não utilizar o comércio local. Os serviços bancários desenvolvidos na sede do distrito foram avaliados como péssimo por grande parte dos entrevistados $(65,12 \%)$ enquanto outros 23,26\% afirmaram não utilizar qualquer serviço bancário no distrito. Os serviços de saúde foram avaliados como bom por $29,07 \%$ dos participantes e como regular por 22,09\%, apresentando, ainda, 23,26\% que declararam não utilizar esses serviços na sede do distrito. Por fim, os serviços de educação, considerados os mais bem avaliados, foram tidos como bom por $45,35 \%$ dos entrevistados, e outros 31,40\% declararam não os utilizar (Fig. 4).

Figura 4: Avaliação dos moradores acerca de equipamentos urbanos de comércio, serviços bancários, saúde e educação na sede do distrito de Cipolândia.

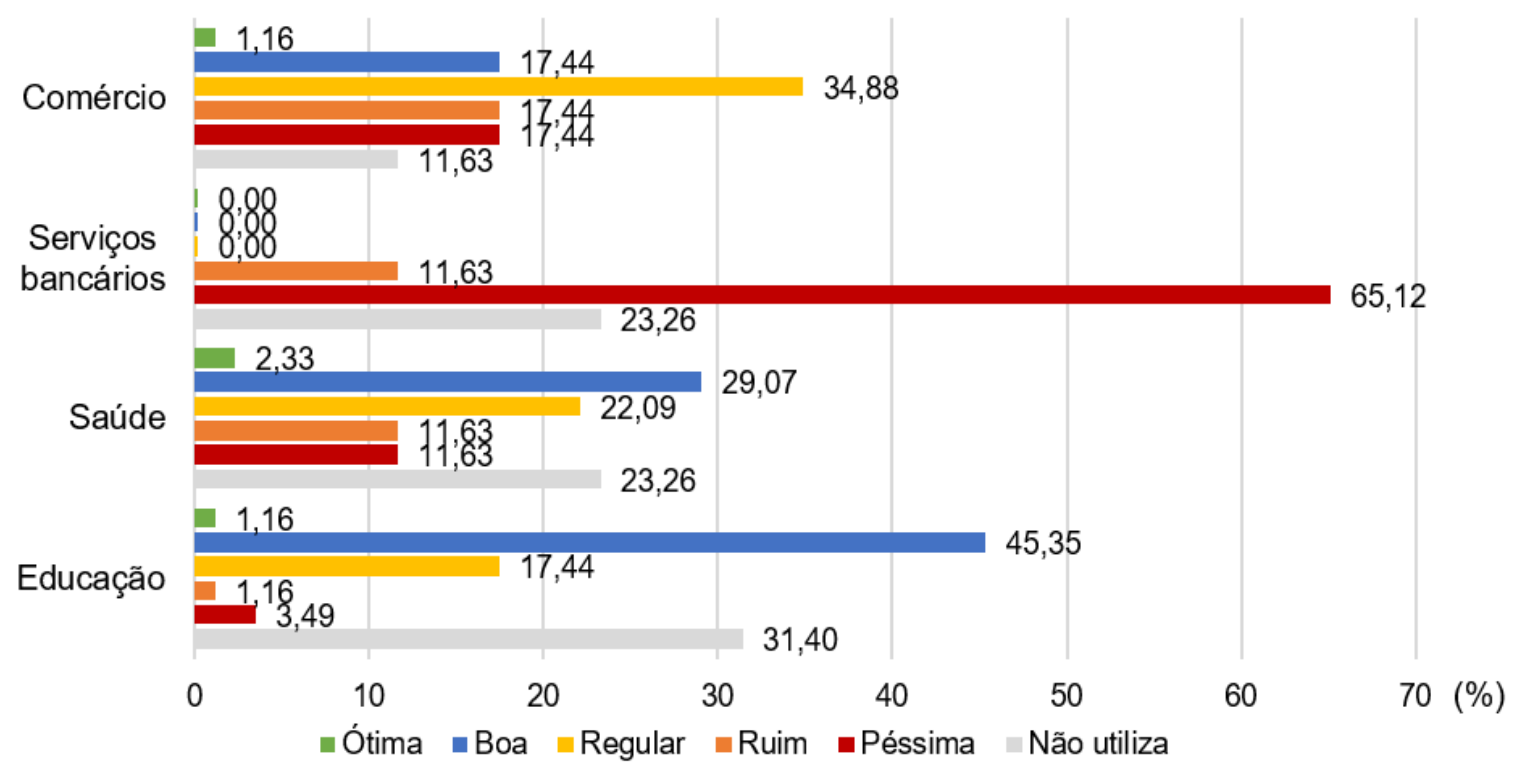

Outros equipamentos urbanos para o atendimento às necessidades imediatas da população dispostos na sede do distrito constam do Quadro 1.

Quadro 1: Equipamentos urbanos dispostos na sede do distrito de Cipolândia.

\begin{tabular}{|c|c|c|}
\hline \multicolumn{2}{|l|}{ Tipo } & Equipamento Existente \\
\hline \multicolumn{2}{|c|}{ Circulação e transporte } & Logradouros públicos, transporte coletivo e escolar. \\
\hline \multicolumn{2}{|c|}{ Cultura e religião } & Igrejas e cemitério. \\
\hline \multicolumn{2}{|l|}{ Esporte e lazer } & Praça, campo de futebol e clube de laço. \\
\hline \multirow{3}{*}{ Infraestrutura } & Comunicações & Correio, rádio, televisão e telefonia. \\
\hline & Energia & Energia elétrica. \\
\hline & Saneamento & Abastecimento de água, coleta de lixo. \\
\hline \multicolumn{2}{|c|}{ Segurança pública e proteção } & Posto policial. \\
\hline \multicolumn{2}{|l|}{ Abastecimento } & Mercado, mercearia, bar, material de construção. \\
\hline \multicolumn{2}{|c|}{ Administração pública } & - \\
\hline \multicolumn{2}{|c|}{ Assistência social } & Centro comunitário. \\
\hline \multicolumn{2}{|l|}{ Educação } & Escola municipal. \\
\hline \multicolumn{2}{|l|}{ Saúde } & Posto de saúde (ESF) \\
\hline
\end{tabular}




\section{A relação dos moradores de Cipolândia com a rede urbana imediata}

Conforme a Figura 5m a sede do distrito de Cipolândia liga-se ao distrito sede do município, a cidade de Aquidauana, por meio da MS-345 em um percurso de aproximadamente $61,1 \mathrm{Km}$. Também se liga à cidade de Anastácio, por meio da MS-345, em percurso de 68,6 Km; à cidade de Terenos, pelas MS-447 e MS-352, em trajeto de 77,3 Kms; e à cidade de Campo Grande, em percurso pelas rodovias MS-447, MS-352 e BR-262, totalizando de 94,4 a $105 \mathrm{Km}$ de distância, conforme a via. Toda rota de acesso à sede distrito de Cipolândia, tanto pela MS-345 quanto pelas MS-447 e MS-352, é feita por meio de rodovias não pavimentadas (Agência Estadual de Gestão de Empreendimentos [AGESUL], 2018).

Figura 5: Sistema rodoviário e articulação do distrito de Cipolândia no contexto de Mato Grosso do Sul.

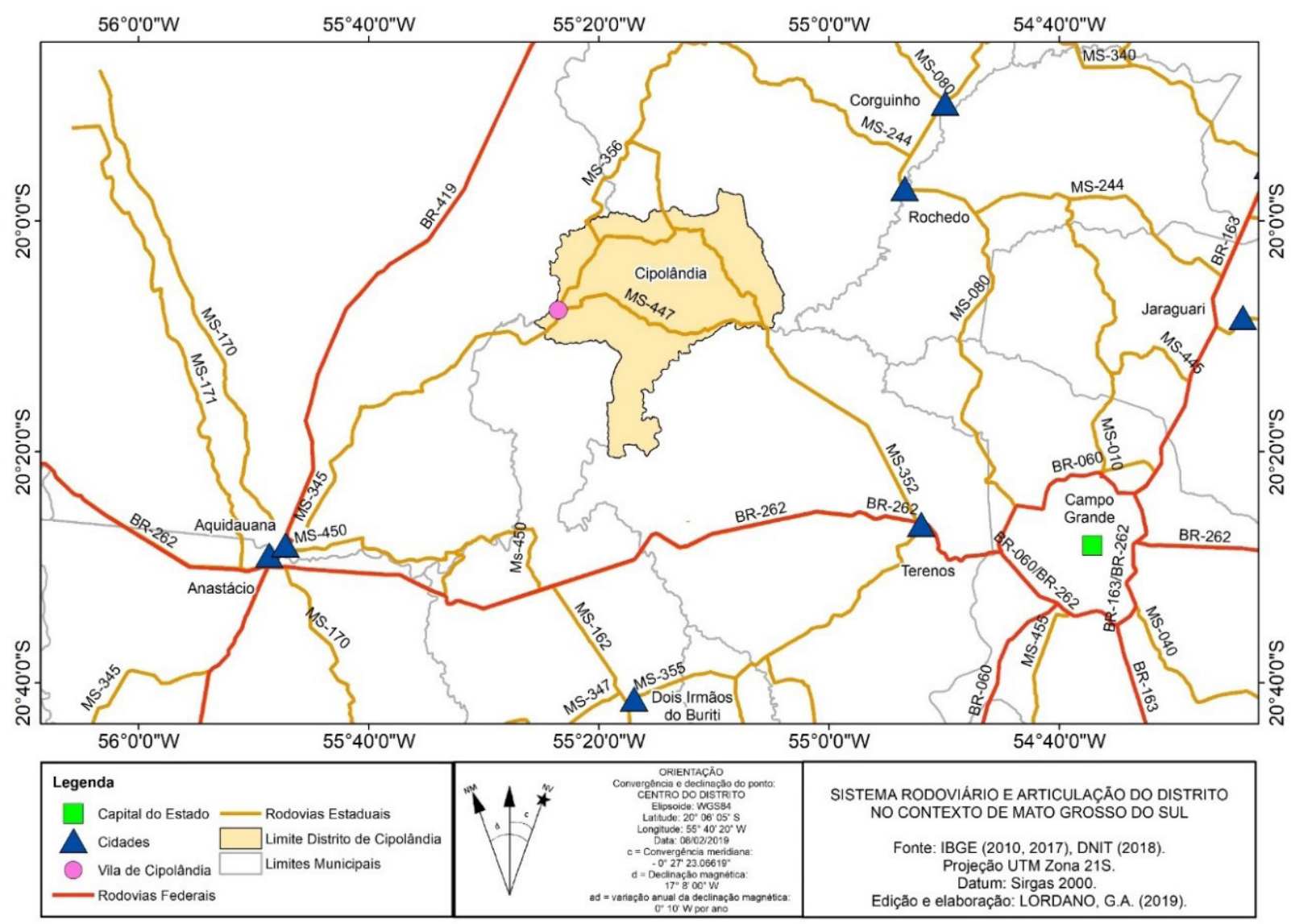

A análise dos dados aponta Aquidauana (Centro de Zona A, sensu IBGE, 2008) como a cidade de maior influência sobre os moradores de Cipolândia, que para lá se dirigem em 59,30\% dos casos. A cidade de Campo Grande (Capital Regional) é o destino de outros $38,37 \%$ dos deslocamentos. Logo, estes dois centros urbanos praticamente "monopolizam" a influência sobre os moradores do distrito (Tab. 2). 
Tabela 2: Cidade destino dos deslocamentos cotidianos dos moradores do distrito de Cipolândia.

\begin{tabular}{l|l|l}
\hline Cidade de destino Predominante & $\%$ & $\mathbf{n}^{\mathbf{0}}$ \\
\hline Aquidauana & 59,30 & 51 \\
\hline Campo Grande & 38,37 & 33 \\
\hline Anastácio & 1,16 & 1 \\
\hline Não soube especificar/ Variável & 1,16 & 1 \\
\hline Total & 99,99 & 86 \\
\hline
\end{tabular}

Campo Grande apresenta centralidade consolidada em Mato Grosso do Sul em vários aspectos distintos. Possui Nível de Centralidade 4, ante 7 de Aquidauana, quanto à localização das empresas. Além disso, constitui-se maior centro de diversidade do comércio (Nível 2), ofertando produtos para um grande volume de população local e distribuindo para a região de influência de entorno, como Aquidauana (Nível 4). Por ser uma área densamente ocupada, Campo Grande apresenta maior diversidade de oferta de serviços (Nível 3), já que quanto maior a população maior também será a demanda de serviços de transporte, comunicação, educação, atividades imobiliárias, saúde, atividades recreativas e serviços pessoais e domésticos, entre outros. Por outro lado, Aquidauana (Nível 5), entre as cidades que detêm alguma influência na rede urbana do estado de Mato Grosso do Sul, figura no nível mais básico de diversificação das atividades de serviços (IBGE, 2008).

Dessa forma, a preferência dos que se deslocam a Aquidauana em detrimento a Campo Grande, parece transcender a hierarquia que a respectiva cidade ocupa na rede urbana, pois essa, na teoria, aponta para o maior poder de atração da capital Campo Grande. Sobre isto, devem-se considerar outros aspectos geográficos que se relacionam e influenciam a decisão individual dos indivíduos nos .seus deslocamentos. Um deles vai ao sentido da constatação obtida por Cortês (2006), que evidenciava a tendência de que, frente à carência de serviços e produtos, os deslocamentos dos moradores do campo direcionavam-se aos núcleos mais próximos, ainda que apresentassem relativa distância. Este é o caso da cidade de Aquidauana, distante aproximadamente $65 \mathrm{~km}$ da sede do distrito, enquanto Campo Grande, apesar de constituir-se numa cidade com muito mais condições de atender às demandas em quase todas as necessidades dos moradores, encontra-se distante aproximadamente $100 \mathrm{Km}$. Na Tabela 3 observa-se que a cidade acessada pelos moradores do distrito de Cipolândia tende a variar de acordo com a motivação para o deslocamento, ou seja, com a demanda que se busca suprir na rede urbana. 
Tabela 3: Cidade de destino considerando o motivo para o deslocamento até a cidade.

\begin{tabular}{|c|c|c|c|c|c|c|c|c|c|c|}
\hline \multirow{2}{*}{$\begin{array}{l}\text { Cidade } \\
\text { Destino Predominante }\end{array}$} & \multicolumn{2}{|c|}{ Anastácio } & \multicolumn{2}{|c|}{ Aquidauana } & \multicolumn{2}{|c|}{$\begin{array}{l}\text { Campo } \\
\text { Grande }\end{array}$} & \multicolumn{2}{|c|}{$\begin{array}{l}\text { Não soube } \\
\text { especificar/ Variável }\end{array}$} & \multicolumn{2}{|c|}{ Total } \\
\hline & $\%$ & $\mathrm{~N}^{\circ}$ & $\%$ & $\mathrm{~N}^{\circ}$ & $\%$ & $\mathrm{~N}^{\circ}$ & $\%$ & $\mathrm{~N}^{\circ}$ & $\%$ & $\mathrm{~N}^{\circ}$ \\
\hline Compras casa e pessoais & 0,00 & 0 & 62,50 & 20 & 37,50 & 12 & 0,00 & 0 & 100 & 32 \\
\hline Lazer e diversão & 0,00 & 0 & 0,00 & 0 & 100 & 1 & 0,00 & 0 & 100 & 1 \\
\hline Levar alguém à cidade & 0,00 & 0 & 40,00 & 2 & 60,00 & 3 & 0,00 & 0 & 100 & 5 \\
\hline Pagamento de contas & 0,00 & 0 & 91,67 & 11 & 8,33 & 1 & 0,00 & 0 & 100 & 12 \\
\hline Receber pagamento ou aposentadoria & 0,00 & 0 & 53,33 & 8 & 40,00 & 6 & 6,67 & 1 & 100 & 15 \\
\hline Saúde/Consultas ou exames médicos & 5,88 & 1 & 35,29 & 6 & 58,82 & 10 & 0,00 & 0 & 100 & 17 \\
\hline Trabalho & 0,00 & 0 & 100 & 4 & 0,00 & 0 & 0,00 & 0 & 100 & 4 \\
\hline Total Geral & 1,16 & 1 & 59,30 & 51 & 38,37 & 33 & 1,16 & 1 & 100 & 86 \\
\hline
\end{tabular}

A cidade de Aquidauana foi o destino na maioria absoluta dos motivos para os deslocamentos dos entrevistados, com destaque ao pagamento de contas $(91,67 \%)$ e realização de compras pessoais ou para a casa (62,50\%). O fato de a busca por demandas relacionadas ao consumo de itens de uso pessoal se dar dentro do próprio município de origem, evidenciando a importância do comércio local na vida dos moradores rurais, já foi constatado anteriormente por Gomes, Fiúza, Pinto e Remoaldo (2018), no qual a cidade exerce funções de gestão elementares na rede urbana, caracterizada pela atuação restrita à sua área imediata (IBGE, 2008).

Por outro lado, Gomes, Fiúza, Pinto e Remoaldo (2018) apresentam, ainda, que os deslocamentos para fora do município de origem geralmente estão associados à busca por serviços especializados como educação e saúde. Esse fato comprova-se, em parte, na realidade de Cipolândia, pois 58,82\% dos que se deslocavam motivados por questões relacionadas à saúde preferiram a cidade de Campo Grande, sendo referência regional como destino para um conjunto de atividades e para grande número de municípios (IBGE, 2008). Soma-se a isto o fato de Campo Grande ser o destino do único entrevistado que teve como motivação principal a busca por lazer ou diversão na cidade.

\section{CONDIÇÕES DE ACESSIBILIDADE À REDE URBANA}

Entre as estradas e rodovias que permeiam o território do distrito de Cipolândia e que convergem aos núcleos urbanos imediatamente próximos aos moradores, a MS-345 é a mais utilizada para o acesso a rede urbana. Para 70,93\% dos moradores do distrito, a MS-345 é utilizada em algum momento de seu percurso até a cidade. A BR-262 é utilizada por 33,72\%, e as MS-447 e MS-352, respectivamente, são utilizadas por 31,39\% e 23,25\% dos moradores em algum trecho de seus deslocamentos (Tab. 4). Destaca-se que, para acessar a rede urbana, na maioria das vezes, os deslocamentos ocorrem por meio de mais de uma rodovia, portanto os índices apresentados, quando somados, ultrapassam 100\%. 
Tabela 4: Rodovias utilizadas pelos moradores nos deslocamentos até a cidade.

\begin{tabular}{l|l|l}
\hline Rodovia & $\%$ & $\mathbf{n}^{\circ}$ \\
\hline MS-345 & 70,93 & 61 \\
\hline BR-262 & 33,72 & 29 \\
\hline MS-447 & 31,39 & 27 \\
\hline MS-352 & 23,25 & 20 \\
\hline MS-356 & 2,32 & 2 \\
\hline Estrada do Nuara & \\
\hline
\end{tabular}

As rodovias MS-345 e MS-352 são as principais na ligação entre o distrito e a rede urbana, pois ambas convergem da sede do distrito às cidades, respectivamente, de Aquidauana e Campo Grande. As rodovias geridas pelo Governo do Estado (MS-345, MS-447, MS-352 e MS-356) encontram-se implantadas, e a rodovia Federal BR-262 encontra-se pavimentada (pista simples). Já a estrada do Nuara (assim conhecida entre os moradores da região) encontra-se sob jurisdição do município de Terenos e apresenta pavimento em leito natural (AGESUL, 2018).

A relevância da análise das condições para o acesso à rede urbana torna-se quase imperativa quando se considera a reflexão de Corrêa (2018), em referência ao papel que a expansão das rodovias e a aceleração do tráfego exercem na redução da influência dos pequenos centros sob o espaço agrário. As rodovias, entre outros, ampliam o espaço dos fluxos de circulação de mercadorias, de pessoas e de capital, fatores que atuam na definição e, principalmente, na redefinição da área de influência dos centros urbanos.

De modo geral, considerando os dados da observação direta, as rodovias e estradas que ligam o distrito à rede urbana apresentam-se em bom estado de conservação. Pode-se destacar que a MS-345, rodovia mais utilizada e principal ligação à cidade de Aquidauana, é a que apresenta melhor condição de conservação de seu pavimento (Figs. 6 A e 6 B). Por outro lado, a MS-352 (Figs. 6 C e 6 D), principal rodovia para o acesso a Campo Grande, apresenta pavimento com material de rochas de grande espessura que, com o tráfego dos veículos, ficam aparentes e causam grande desconforto nos deslocamentos. Sobre isto, Costa (2018) salienta que, apesar de todos os componentes serem importantes à conservação da rodovia (pavimento, terrapleno, proteção do corpo estradal, obras de arte correntes, obras de arte especiais, sinalização, obras complementares etc.), o componente pavimento prevalece, no tocante às características de segurança e de conforto dos usuários.

3 A denominação Estrada do Nuara faz alusão a uma pequena comunidade na proximidade, sob jurisdição do município de Terenos, e constitui a principal ligação dos moradores da porção Sul do distrito de Cipolândia à rede urbana, sobretudo dos moradores da localidade Chácara Bacuri. 
Figura 6: Aspecto do pavimento das rodovias MS-345 e MS-352.
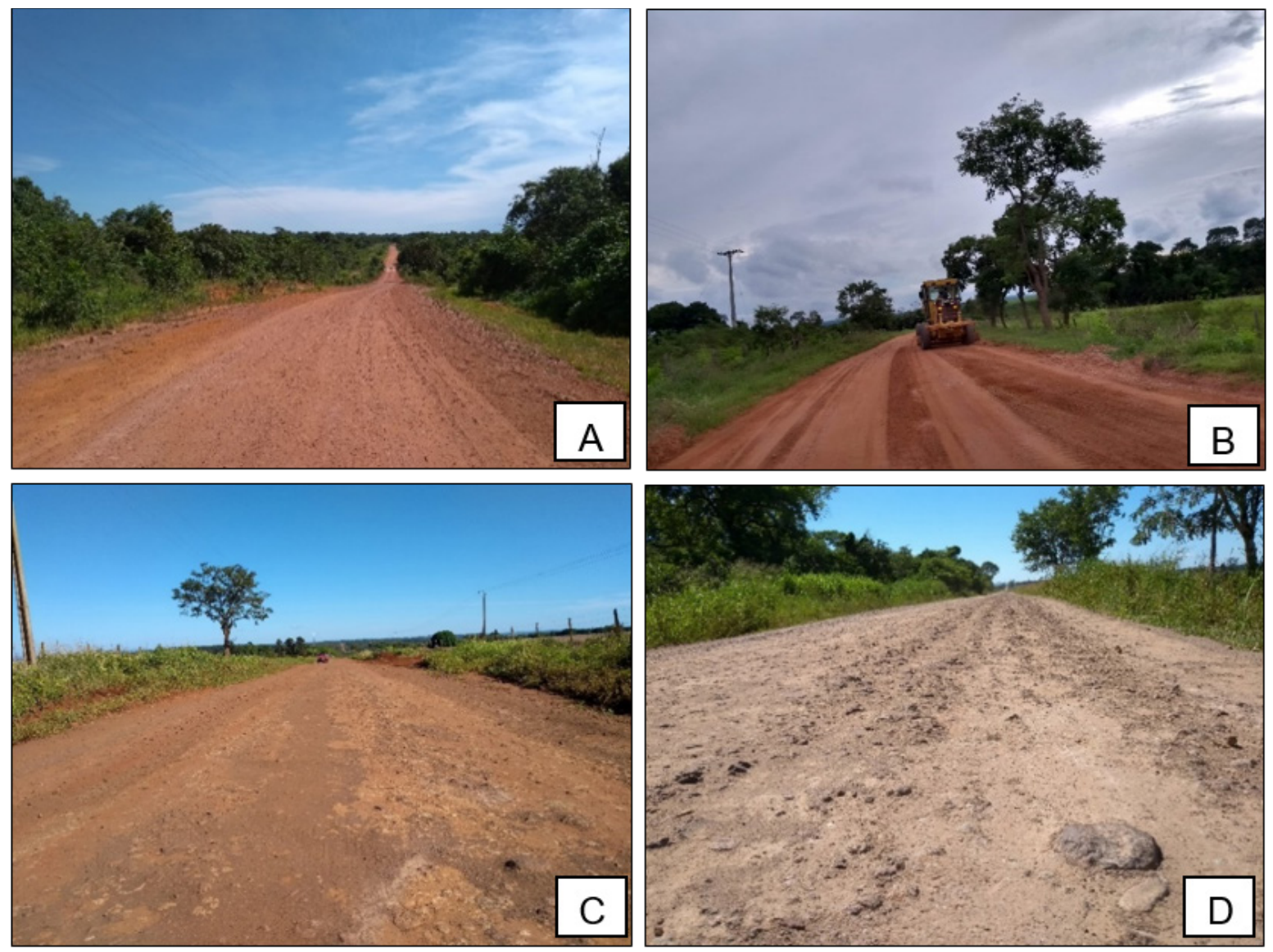

A ausência de pavimentação asfáltica nas rodovias que perpassam Cipolândia não é uma exclusividade do distrito; longe disso, pois esse é um cenário recorrente sobretudo nas rodovias e estradas sob jurisdição dos municípios ou do estado de Mato Grosso do Sul, como se pode observar no Quadro 2, que apresenta um compilado de informações do ano de 2018 obtidas no relatório do Sistema Rodoviário do Estado (SRE), da Agência Estadual de Gestão de Empreendimentos (AGESUL).

Quadro 2: Rede rodoviária estadual, municipal e federal no Estado de Mato Grosso do Sul.

\begin{tabular}{|c|c|c|c|c|c|}
\hline Rede Rodoviária & Situação & Federal (km) & Estadual (km) & Municipal (km) & Total $(\mathbf{k m})$ \\
\hline \multicolumn{2}{|l|}{ Planejada } & 522 & $1.911,8$ & 50,7 & $2.484,5$ \\
\hline \multirow{5}{*}{$\begin{array}{l}\text { Rede Não } \\
\text { Pavimentada (km) }\end{array}$} & Leito Natural & 225,5 & $2.156,8$ & $42.062,1$ & $44.444,4$ \\
\hline & Em Obras de Implantação & - & - & - & - \\
\hline & Implantada & 21,8 & $6.390,9$ & $3.064,0$ & $9.476,7$ \\
\hline & Em Obras de Pavimentação & - & 69,5 & - & 69,5 \\
\hline & Subtotal & 247,3 & $8.617,2$ & $45.126,1$ & $53.990,5$ \\
\hline \multirow{4}{*}{$\begin{array}{l}\text { Rede Pavimentada } \\
(\mathrm{km})\end{array}$} & Pista Simples & $4.056,8$ & $4.509,6$ & - & $8.566,4$ \\
\hline & Em Obras de Duplicação & - & - & - & - \\
\hline & Pista Dupla & 90,1 & 29,6 & - & 119,7 \\
\hline & Subtotal & $4.146,9$ & $4.539,3$ & - & $8.686,2$ \\
\hline \multicolumn{2}{|l|}{ Total $(\mathrm{km})$} & $4.916,2$ & $15.068,2$ & $45.176,8$ & $65.161,2$ \\
\hline
\end{tabular}

Fonte: elab. a partir de AGESUL (2018). 
Das demais vias analisadas, a BR-262 (Fig. 7 A) não aparenta qualquer problema para o deslocamento, porque, totalmente pavimentada, é uma das principais rodovias de trânsito pelo estado de Mato Grosso do Sul. A MS-447 (Fig. 7 B), apesar de um pouco sinuosa em alguns trechos e com muitas pontes sobre córregos (Fig. 7 C), apresenta uma boa qualidade, não sendo identificado nenhum ponto mais crítico. Por fim, a MS-356 (Fig. 7 D), a menos utilizada pelos moradores do distrito no acesso à rede urbana, também possui, ao menos nos pontos observados, boa manutenção e nenhum problema significativo aparente.

Figura 7: Aspecto das rodovias BR-262, MS-447 e MS-356.
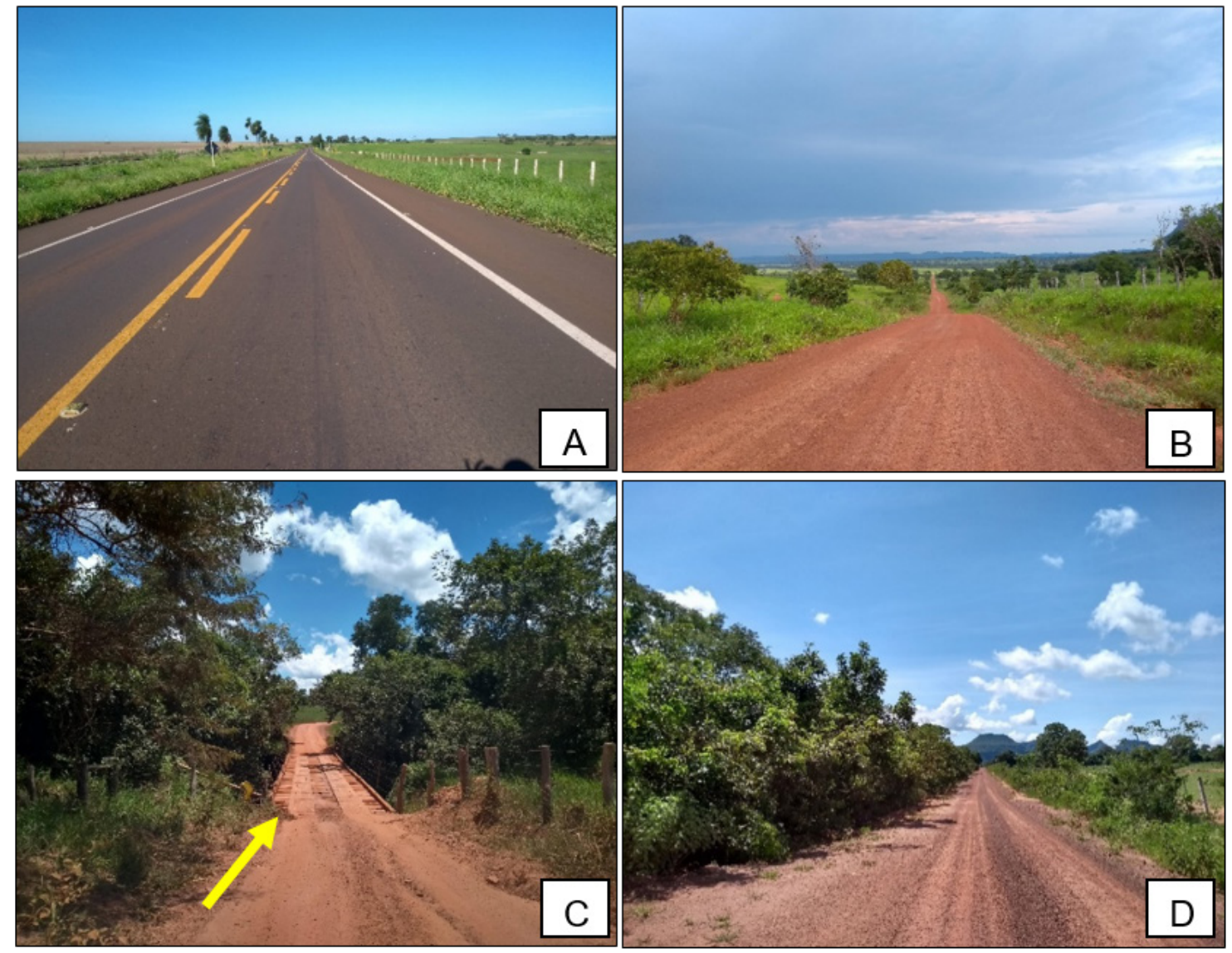

Por outro lado, alguns pontos mais críticos na malha viária utilizada no acesso às cidades foram identificados. Destaca-se, nesse sentido, a característica geral da Estrada do Nuara, a qual, fora da jurisdição do Estado ou da União, é a que claramente tem sua manutenção e estrutura mais deficitárias (Fig. 8 A). Nesta estrada foi constatada a situação mais grave, relacionada a uma ponte sobre o rio Aquidauana na divisa entre os municípios de Aquidauana e Terenos. Aparentemente, a ponte não recebe a devida manutenção face à sua importância naquela localidade, sendo constatados vários buracos em sua pista ocasionados pelo apodrecimento da madeira (Fig. 8 B).

Outro fator que não pode ser negligenciado é que, apesar da condição aceitável das estradas como um todo, como identificadas em campo, no período de chuvas mais intensas, ocorre significativa piora nas condições das vias. A Figura $8 \mathrm{C}$, a seguir, de autoria de um morador da região e feita no mês de fevereiro de 2019, mostra uma ponte com a cabeceira 
totalmente danificada pelas chuvas na MS-345, entre a sede do distrito de Cipolândia e o entroncamento com a MS-356. Outro fato a ser considerado e que requer cautela nas rodovias disponíveis para os deslocamentos, são as constantes comitivas de transporte de gado bovino, frequentemente percebidas nas incursões a campo (Fig. 8 D).

Figura 8: Pontos críticos nas rodovias para os deslocamentos até a cidade.

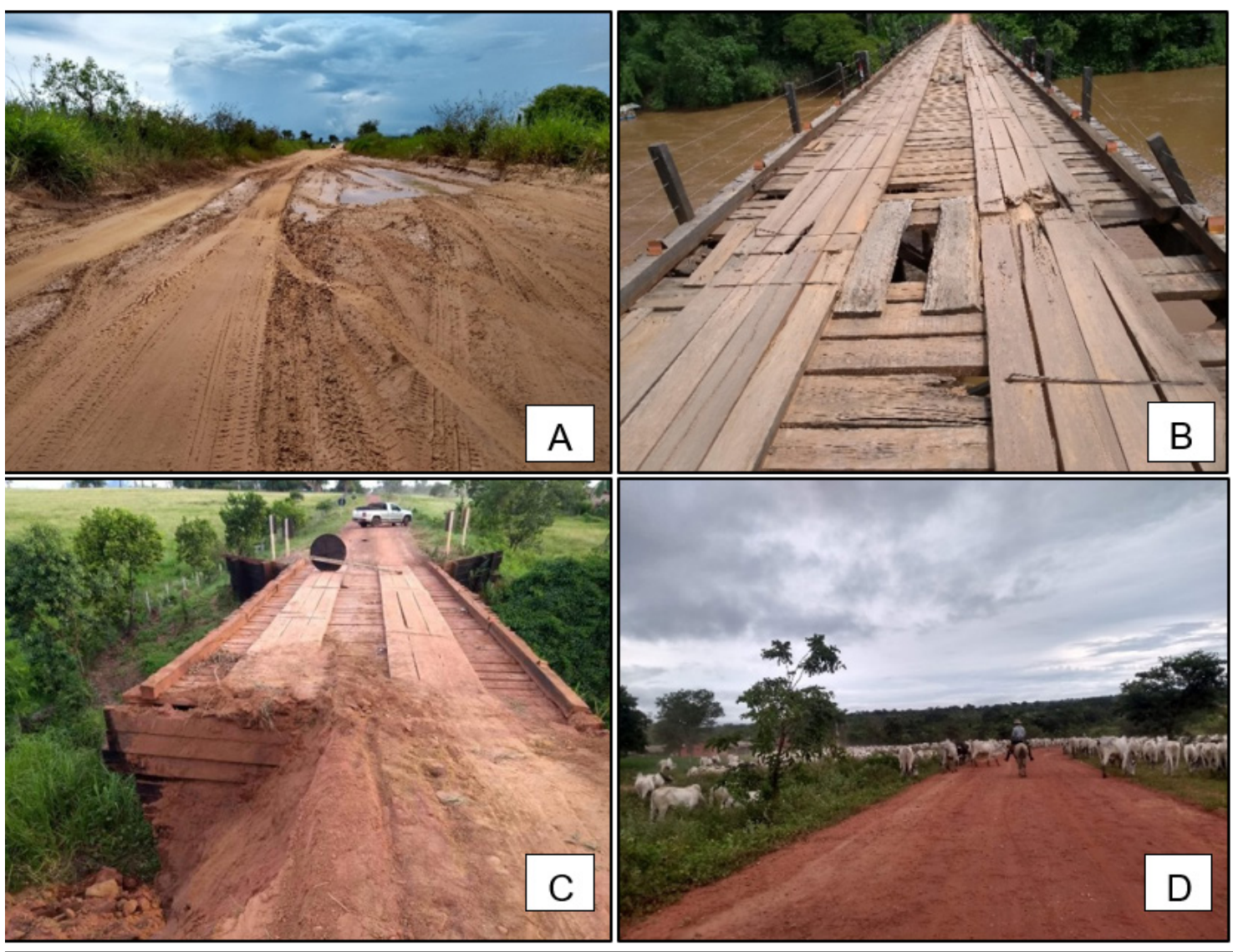

Foto C: E.B. Barbosa, 2019.

\section{CONCLUSÕES}

Esse artigo possibilitou uma visão parcial sobre a relação dos moradores do distrito de Cipolândia com a rede urbana do estado do Mato Grosso do Sul, assim como permitiu um panorama de como a sede do distrito emerge enquanto o primeiro contato dos moradores rurais com um centro urbano e suas funções, equipamentos, bens e serviços.

Entre os pontos que chamaram mais atenção, pode-se destacar que a sede do distrito apresenta uma estrutura de comércio varejista acanhada e que a atividade industrial se resume à existência de uma indústria de cerâmica. A presença estatal dá-se nos equipamentos mais elementares, como escola, posto de saúde, serviços de correios e distribuição de água tratada. Contudo, considerando o pequeno porte do núcleo e do distrito como um todo, a sede pode ser percebida como o primeiro contato dos moradores da região com a 
rede urbana e, consequentemente, com a função urbana mais básica que lhe é própria: a distribuição de bens e de serviços, ainda que de forma incipiente. Assim a sede distrital, guardadas as devidas proporções, pode ser entendida como um ponto inicial de acesso à rede urbana, sobretudo quando considerado o desempenho de funções urbanas básicas para a população interna e de sua hinterlândia imediata.

No entanto, a estrutura de equipamentos para a distribuição de bens e de serviços no distrito de Cipolândia não permite a definição de uma condição de autossuficiência no acesso às funções urbanas, tampouco assevera o grau em que os moradores delas se utilizem cotidianamente. Nesse sentido, os deslocamentos às cidades não necessariamente são inteiramente justificados pelas ausências no distrito, assim como a dinâmica da mobilidade cotidiana não pressupõe uma explicação da oferta de funções urbanas nele disponível.

Quanto ao acesso dos moradores à cidade, é latente que a cidade de Aquidauana é a que os moradores de Cipolândia preferem quando buscam satisfazer as demandas de sua vida cotidiana fora do distrito. Nela são satisfeitas suas necessidades de primeira hora, como as compras e os serviços bancários, sobretudo o recebimento de aposentadoria e o pagamento de contas. Já a capital do estado, Campo Grande, é o centro urbano que canaliza a busca pelos serviços mais especializados, como os de saúde, por exemplo. Esses dados, de maneira geral, são um reflexo da posição das respectivas cidades na hierarquia da rede urbana regional.

As condições de manutenção das estradas e rodovias para o acesso às cidades são, de forma geral, satisfatórias, contudo há exceções como a MS-352 e a Estrada do Nuara, ambas utilizadas majoritariamente para acessar a capital, e que apresentam pavimento em situação mais adversa.

Isto posto, salienta-se que o maior detalhamento do nível de influência da sede distrital na vida de seus moradores, ou ainda da influência das cidades sobre o distrito com um todo, será possível somente com o desenvolvimento de pesquisas posteriores, em Cipolândia ou noutra comunidade com características semelhantes. Por fim, espera-se que esse artigo contribua com o aperfeiçoamento do debate sobre o distrito e sua relação com a rede urbana.

\section{REFERÊNCIAS}

Abramovay, R. (2000). Funções e medidas da ruralidade no desenvolvimento contemporâneo. (IPEA Texto para Discussão, 702). Recuperado de: https:// www.ipea.gov.br/portal/images/stories/PDFs/TDs/td_0702.pdf.

Agência Estadual de Gestão de Empreendimentos (2018). Sistema Rodoviário do Estado de Mato Grosso do Sul. Recuperado de http://www.agesul.ms.gov.br/wp-content/uploads/2019/01/SRE_2018.pdf.

Antunes, M.V.M., \& Hespanhol, R.A.M. (2018). Os distritos municipais no Brasil: uma leitura geográfica a partir de Jamaica e Jaciporã, município de Dracena (São Paulo/Brasil). Revista Geo UERJ, (32):1-32. Recuperado de https://www.e-publicacoes.uerj.br/index.php/geouerj/article/view/24942/24747 doi: 10.12957 /geouerj.2018.24942

Babbie, E. (1999). Métodos de Pesquisas de Survey. Belo Horizonte: Ed. UFMG. 
Conte, C.H. (2014). Rede urbana: uma breve abordagem teórica. Revista GeoAtos, 1(14):76-93. Recuperado de https://revista.fct.unesp.br/index.php/geografiaematos/article/view/2625. Doi.org/10.35416/geoatos. v1i14.2625

Cortês, C.P. (2006). As atividades rurais como fomentadoras de fluxos e o deslocamento da população rural no município de Sumidouro-RJ. Encontro de Grupos de Pesquisa, Uberlândia, MG, Brasil, 2.

Corrêa, R.L. (2000). Rede Urbana e Formação Espacial: uma reflexão considerando o Brasil. Revista Território, 5(8): 121-129. Recuperado de: http://www.laget.eco.br/pdf/08_5_lobato.pdf.

Corrêa, R.L. (2018). Caminhos Paralelos e Entrecruzados. São Paulo: Ed. UNESP.

Costa, M.M. (2018). Efeito do uso do Latossolo Vermelho-Amarelado na BR 419 e na MS-345 em Aquidauana/MS. 2018 (Dissertação de Mestrado). Universidade Federal de Mato Grosso do Sul, UFMS, Aquidauana, MS, Brasil. Recuperado de https:// posgraduacao.ufms.br/portal/trabalho-arquivos/download/5418.

Gomes, N.F.M., Fiúza, A.L.C., Pinto, N.M.A., \& Remoaldo, P.C.A. (2018). Os rurais e a cidade: a mobilidade socioespacial dos habitantes do campo em pequenos municípios de economia agrícola. $R a^{\prime} e^{\prime} g a$, 44:242-257. Recuperado de https:/ / revistas.ufpr.br/raega/article/view/50204/35327. DOI: 10.5380/raega

Instituto Brasileiro de Geografia e Estatística (2008). Regiões de influência das cidades 2007. Rio de Janeiro. Recuperado de https://www.mma.gov.br/estruturas/PZEE/_arquivos/regic_28.pdf.

Instituto Brasileiro de Geografia e Estatística (2010). Censo demográfico de 2010, Sinopse por Setores. Recuperado de https:/ / censo2010.ibge.gov.br/sinopseporsetores/?nivel=st.

Instituto Brasileiro de Geografia e Estatística (2013a). Atlas do censo demográfico 2010 / IBGE. Rio de Janeiro. Recuperado de https:/ / biblioteca.ibge.gov.br/index.php/biblioteca-catalogo?view=detalhes\&id=264529.

Instituto Brasileiro de Geografia e Estatística (2013b). Pesquisa Nacional por Amostra de Domicílios 2013. (Relatório de Pesquisa, 33). Recuperado de https://biblioteca.ibge.gov.br/visualizacao/periodicos/59/ pnad_2013_v33_br.pdf.

Instituto Brasileiro de Geografia e Estatística (2018). Aquidauana. Recuperado de https:/ / cidades.ibge.gov. $\mathrm{br} / \mathrm{brasil} / \mathrm{ms} /$ aquidauana/panorama.

Instituto Brasileiro de Geografia e Estatística (2019). Portal de mapas do IBGE. Recuperado de https:// portaldemapas.ibge.gov.br/portal.php\#homepage.

Keller, E.C.S. (1970). O “habitat” rural. In A. Azevedo (org.). Brasil a terra e o homem. São Paulo: Nacional. v.2.

Joia, P.R. (2005). Origem e Evolução da Cidade de Aquidauana-MS. Revista Pantaneira, 7:34-49. Recuperado de https://periodicos.ufms.br/index.php/revpan/issue/view/164.

Pina, J.H.A., Lima, O. A., \&Silva, V.P (2008). Município e Distrito: um estudo teórico. Campo-Território: revista de geografia agrária, 3(6):125-142. Recuperado de http://www.seer.ufu.br/index.php/campoterritorio/ article/view/11851/6937.

Robba, C. (1992). Aquidauana ontem e hoje. Campo Grande: Tribunal de Justiça de Mato Grosso do Sul.

Silva, L.F., Cunha, E.R., \& Bacani, V.M. (2018). Zoneamento Ambiental de Bacia Hidrográfica Ocupada por Assentamento Rural: Estudo de Caso do Córrego Indaiá- MS. Revista Geografia, Ensino \& Pesquisa, 22(11):1-12. Recuperado de https://periodicos.ufsm.br/geografia/article/view/27352. doi. org/10.5902/2236499427352.

Silva, M.A.S. (2014). Distritos municipais: entre a modernidade da cidade e a tradição do campo. Seminário Estadual de Estudos Territoriais, Ponta Grossa, PR, Brasil, 7. Recuperado de https://www3.uepg.br/ seet/wp-content/uploads/sites/5/2014/08/distritos-municipais-entre-a-modernidade-da-cidade-e-atradi\%c3\%87\%c3\%83o-do-campo.pdf.

Data de submissão: 03/out./2020

Data de aceite: 07/out./2020 